\title{
PERAMALAN TREND KUNJUNGAN WISATAWAN DIKAWASAN KONSERVASI MANGROVE BEKANTAN (KKMB) DI KOTA TARAKAN
}

\author{
Galih Yogi Rahajeng', Arni Arni². \\ ${ }^{1,2}$ Universitas Borneo Tarakan, Fakultas Pertanian, Program Studi Agribisnis \\ Jl. Amal Lama no 1, Tarakan Timur, Tarakan. \\ E-Mail: Ajeng_GYR@yahoo.com
}

Received: 4 July 2019

Accepted: 20 September 2019

\begin{abstract}
Conservation Area for Mangrove and Proboscis in Tarakan City was built to preserve mangrove ecosystems and wildlife in its development and alternative ecotourism destinations. Based on the potential of Conservation Area for Mangrove and Proboscis in Tarakan City, therefore this study aims to predict the trend of tourist visits in Conservation Area for Mangrove and Proboscis in Tarakan City so that it can become the foundation for the development of Conservation Area for Mangrove and Proboscis inTarakan City in the future. In this study using respondents as many as 100 respondents who were Conservation Area for Mangrove and Proboscis in Tarakan City visitors. The sampling used method was accedential sampling and quota sampling. The result shown than visitors of Conservation Area for Mangrove and Proboscis inTarakan from 2018-2022 estimated to reach $164,888,5$ visitors. The average decrease in visits per year is 978 people. Because of the facilities in the Conservation Area for Mangrove and Proboscis in Tarakan City are inadequate, such as wooden bridge that begin to be damaged and slippery when it rains, lack of place to sit, cleanliness that has not been maintained, unsanitary toilets, and lack of parking areas, and reduced proboscis monkey. If there is no renovation and repair of facilities, visitors tend not to choose the Conservation Area for Mangrove and Proboscis in Tarakan City as an alternative tourist attractions.
\end{abstract}

Keywords: Conservation of mangrove, Ecotourism, Trend Analysis.

\begin{abstract}
ABSTRAK
Kawasan Konservasi Mangrove dan Bekantan Kota Tarakan (KKMB) dibangun dan memiliki tujuan sebagai pengembangan satwa liar dan ekowisata alternatif. Berdasarkan potensi yang ada, oleh karena itu maka penelitian ini bertujuan untuk meramalkan trend kunjungan wisatawan di KKMB agar dapat menjadi landasan dalam pengembangan KKMB di masa depan. Dalam penelitian ini menggunakan 100 responden yang merupakan pengunjung KKMB. Metode pengambilan sampel yang digunakan adalah pengambilan sampel akedensial dan kuota. Hasil Penelitian memperlihatkan pengunjung KKMB di Kota Tarakan dari 2018-2022 diperkirakan mencapai $164.888,5$ orang. Penurunan rata-rata kunjungan per tahun adalah 978 orang. Karena fasilitas di Kawasan Konservasi Mangrove dan Bekantan Kota Tarakan tidak memadai, seperti jembatan kayu yang mulai rusak dan licin saat hujan, kurangnya tempat duduk, kebersihan yang belum dijaga, toilet yang tidak bersih, dan kurangnya area parkir, dan berkurangnya populasi bekantan. Jika tidak ada renovasi dan perbaikan fasilitas, pengunjung cenderung tidak memilih Kawasan Konservasi Mangrove Bekantan di Kota Tarakan sebagai tempat wisata alternatif.
\end{abstract}

Kata kunci: Konservasi mangrove, Ekowisata, Analisis Trend.

\section{PENDAHULUAN}

World Travel \& Tourism Council pada Tourism in the Green Economy Report (2016) menyatakan bahwa pilihan wisatawan dipengaruhi oleh pertimbangan keberlanjutan pariwisata. WTO juga memprediksi bahwa ekowisata akan tumbuh pesat pada dua dekade selanjutnya, begitu juga dengan pendapatannya. Trend pariwisata dalam era modern ini telah bergeser dari wisata masal berubah haluan menjadi wisata minat khusus, hal ini dikarenakan kejenuhan wisatawan akan destinasi wisata. Indonesia memiliki 7 potensi jenis wisata minat khusus, yaitu sejarah dan budaya, alam dan ekowisata, kuliner dan belanja, olahraga dan rekreasi yang dapat dikembangkan. Oleh karena itu Direktur Jenderal Konservasi Sumber Daya Alam dan Ekosistem (2016) menyatakan bahwa pemerintah akan meningkatkan wisatawan ke kawasan konservasi, mengingat banyaknya 
jumlah wisatawan domestik yang berkunjung ke objek wisata konservasi per tahunnya yang mencapai 4 juta wisatawan, termasuk 300.000 wisatawan mancanegara.

Kota Tarakan merupakan sebuah kota yang berada di Propinsi Kalimantan Utara dengan luas mencapai 250,80 $\mathrm{Ha}$ dengan populasi penduduk 239.787 jiwa, kota ini memiliki semboyan yang dikenal dengan istilah BAIS (Bersih, Aman, Indah, dan Sejahtera), yang memiliki visi menjadikan Tarakan sebagai Little Singapore. Kota Tarakan memiliki hutan mangrove sebagai tempat wisata yang berada di tengah kota yang disebut Kawasan Konservasi Konservasi Mangrove dan Bekantan (KKMB). Bekantan selain dikenal sebagai maskot Ancol, juga merupakan ikon pariwisata Kota Tarakan.

Kawasan Konservasi Mangrove Bekantan di Tarakan yang ditujukan untuk melestarikan ekosistem mangrove dan satwa liar dalam perkembangannya diarahkan sebagai daerah tujuan ekowisata alternatif (Direktur Jenderal Konservasi Sumber Daya Alam dan Ekosistem, 2014). Ekowisata memberikan kesempatan bagi para wisatawan untuk menikmati keindahan alam dan budaya lokal serta mempelajari tentang pentingnya berbagai ragam mahluk hidup yang ada di dalamnya. Selain itu, kegiatan ekowisata juga dapat meningkatkan pendapatan untuk pelestarian alam serta menghasilkan keuntungan ekonomi bagi kehidupan masyarakat di sekitarnya (Subadra, 2008).

Pengelolaan hutan mangrove yang berkelanjutan dirasakan sangat penting oleh Pemerintah Kota Tarakan, sehingga pada tahun 2001 ditetapkan Kawasan Konservasi Mangrove Bekantan (KKMB) seluas 9 Ha dengan tujuan untuk melindungi ekosistem mangrove termasuk di dalamnya satwa endemik Kalimantan yaitu bekantan, penetapan KKMB diikuti dengan pembangunan fasilitas pada tahun 2003 berupa jembatan, menara pengamatan, gazebo, perpustakaan, dan karantina untuk pemeriksaan satwa. Pada tahun 2006, KKMB diperluas menjadi 22 ha atas kesepakatan dan dukungan Pemerintah Kota Tarakan dan DPRD Kota Tarakan (Save Our Environment, 2012). Berdasarkan potensi yang ada, oleh karena itu maka penelitian ini bertujuan untuk meramalkan trend kunjungan wisatawan di KKMB agar dapat menjadi landasan dalam pengembangan KKMB di masa depan.

\section{METODE PENELITIAN \\ Lokasi penelitian}

Penelitian ini dilaksanakan di Kawasan

Konservasi Mangrove Bekantan Kecamatan Tarakan Barat Kota Tarakan.

\section{Metode Penentuan Sampel}

Metode pengambilan sampel yang digunakan adalah "Accidential sampling" dan "Kuota Sampling" yaitu teknik penentuan sampel yang secara kebetulan bertemu dengan peneliti di lokasi wisata Kawasan Konservasi Mangrove Bekantan Di Kota Tarakan pada saat melakukan penelitian dapat digunakan sebagai sampel apabila, responden tersebut cocok dengan kriteria responden yang telah ditentukan oleh peneliti yaitu telah berkunjung ke Kawasan Konservasi Mangrove Bekantan di Kota Tarakan minimal 2 kali, dan berumur 17 tahun atas pertimbangan pada usia tersebut, responden telah mencapai umur dewasa dimana kemampuan mental telah membantu untuk berfikir dan mampu membuat keputusan untuk melakukan perjalanan wisata. Dalam penelitian ini menggunakan responden sebanyak 100 responden. Hal tersebut bertujuan untuk mendapatkan informasi yang jelas tentang kondisi di lapangan.

\section{Metode Analisis Data}

\section{Analisis Trend}

(time series), yaitu analisis yang ditujukan untuk menganalisis trend jumlah kunjungan wisatawan terhadap Kawasan Konservasi Mangrove Bekantan di Kota Tarakan pada 5 tahun mendatang.

Analisis trend yang digunakan dalam penelitian ini adalah model least squares. Pada penelitian ini analisis trend digunakan untuk mengetahui apakah ada peningkatan jumlah pengunjung ke Kawasan Mangrove Bekantan di Kota Tarakan. Adapun formulasi yang digunakan yaitu (Sulistya, Albertus, 2016):

$\mathrm{Y}=\alpha+\mathrm{bx}$

Keterangan:

$\mathrm{Y}=$ Nilai trend yang ditaksir

$\mathrm{a}=$ Nilai $\mathrm{Y}$ jika $\mathrm{x}=0$

$\mathrm{b}=$ Besarnya perubahan variabel $\mathrm{Y}$ yang terjadi pada setiap perubahan

satu unit variabel $\mathrm{x}$

Nilai a dan $b$ dapat dihitung menggunakan formulasi sebagai berikut:

$$
a=\frac{\sum Y}{n} \quad b=\frac{\sum X Y}{X^{2}}
$$




\section{HASIL DAN PEMBAHASAN Gambaran Umum Lokasi Penelitian}

Kawasan Konservasi Mangrove Bekantan ditetapkan pada tahun 2001 dengan luas $9 \mathrm{Ha}$ dengan tujuan untuk melindungi ekosistem mangrove termasuk di dalamnya satwa endemik Kalimantan yaitu Bekantan (Sawitri.et.al, 2013). Pada Tahun 2003 pengelola KKMB membangun fasilitas berupa jembatan, menara pengamatan, gazebo, perpustakaan, dan karantina untuk pemeriksaan kesehatan satwa. Kemudian, pada tahun 2006 KKMB diperluas menjadi $22 \mathrm{Ha}$ atas kesepakatan dan dukungan pemerintah Kota Tarakan dan DPRD Kota Tarakan. Selain pemerintah, pihak swasta dan LSM juga turut membantu KKMB dalam bentuk restorasi dan penelitian seperti WWF, PT Minanusa Aurora, Nichiel Fresh Ltd, Ganko Food Industries, Provident Indonesia Energy, PT Medco, Dan PT PLN (Badan Pengelolaan Lingkungan Hidup, 2010). Pengembangan KKMB Kota Tarakan ditujukan untuk melestarikan ekosistem mangrove dan satwa liar dalam perkembangan nya diarahkan sebagai daerah tujuan ekowisata alternatif, karena hal tersebut dapat memberikan kesempatan bagi para wisatawan untuk menikmati keindahan alam dan budidaya lokal serta, mempelajari tentang pentingnya berbagai ragam makhluk hidup di hutan yang berada di tengah kawasan perkotaan dan mudah diakses. Hingga saat ini, KKMB Kota Tarakan salah satu ikon Kota Tarakan (Yusuf, 2008).

Kawasan hutan mangrove selain menjadi obyek wisata juga mempunyai fungsi lain yaitu sebagai paru-paru Kota Tarakan serta menjadi benteng yang melindungi kota dari abrasi air laut. Di hutan mangrove ini juga menjadi habitat alami pohon-pohon bakau dan fauna-fauna khas Tarakan. Pohon-pohon yang berada di Hutan Mangrove ini rata-rata sudah berumur puluhan bahkan ratusan tahun. Hutan Mangrove ini juga dijadikan sebagai laboratorium hidup yang dimanfaatkan oleh peneliti-peneliti baik dari dalam maupun luar negeri. Hasil penelitan tersebut sangat bermanfaat bagi ilmu pengetahuan dan juga terdapat hewan-hewan khas yang tinggal didalam hutan.

Diantara hewan-hewan khas tersebut yang paling menarik yaitu bekantan. Bekantan merupakan salah satu hewan yang di lindungi monyet ini beda dengan monyet-monyet lain, yang paling unik dari monyet ini yaitu hidungnya yang panjang. Karena hidungnya yang panjang tersebut monyet ini dijuluki sebagai "Monyet Belanda". Walaupun memiliki tubuh besar bekantan tetap lincah berayun-ayun dari satu dahan ke dahan lain, menjadi hiburan tersendiri bagi pengunjung.

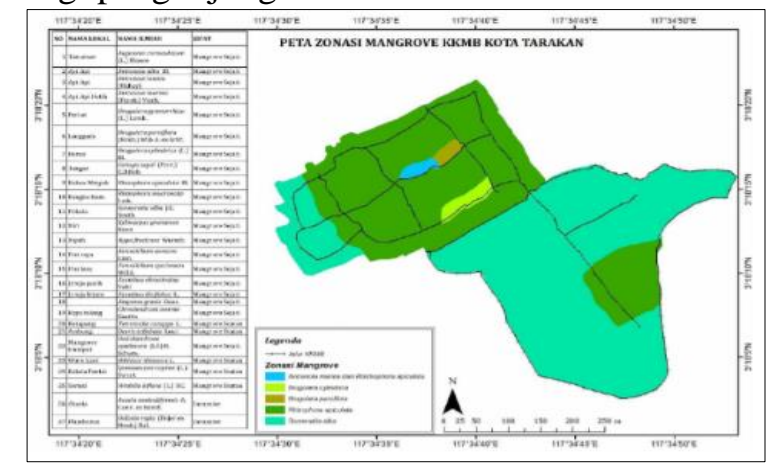

Gambar 1. Peta zonasi mangrove KKMB Kota Tarakan

Hutan Mangrove tersebut sebagian terletak di tengah kota yang disebut Kawasan Wisata Konservasi Mangrove dan Bekantan (KKMB). Kawasan konservasi ini berlokasi di Jalan Gajah Mada dan sebagian KKMB terletak di pinggir pantai letaknya yang berada di jantung kota membuat kawasan wisata ini mudah untuk di temukan. Dari kompleks THM Simpang Tiga yang merupakan pusat keramain Kota Tarakan dengan menggunakan kendaraan umum seperti angkot, hanya memakan waktu sekitar 5 menit, dan akses untuk ke mangrove bisa juga dengan berjalan kaki, letak kawasan hutan mangrove berbatasan langsung dengan komplek Pasar Gusher yang merupakan sentra perekonomian masyarakat Tarakan dan dan kawasan industri cold storage serta pelabuhan Tengkayu II.

Namun KKMB yang berada di pinggir pantai ini tidak bisa dimasuki secara langsung karena pantainya berlumpur dan berair sehingga, pengelola KKMB membuat semacam jembatan kayu sepanjang 2.400meter yang meliuk-liuk melintasi hutan Mangrove ini. Pengunjung yang datang ke KKMB dapat berjalan di atas jembatan kayu selebar 1 meter untuk mengintari areal seluas 22 hektar.

\section{Analisis Trend Jumlah Kunjungan Wisatawan KKMB}

Analisis ini digunakan untuk mengetahui suatu estimasi atau peramalan terhadap jumlah kunjungan di Kawasan Konservasi Mangrove Bekantan di Kota Tarakan pada 5 tahun yang akan datang. Data yang digunakan merupakan data pengunjung tahunan (time series) pada tahun 2013-2017 yang diperoleh dari Kantor Dinas Pariwisata Kota Tarakan. Pencarian nilai tren menggunakan analisis data menggunakan sekuler dengan metode kuadrat terkecil. Berikut ini 
merupakan perhitungan trend dengan metode least square yang terdapat pada tabel 1 .

Tabel 1. Perhitungan Jumlah Kunjungan ke Kawasan Konservasi Mangrove Bekantan Di Kota Tarakan Tahun 2013-2017.

\begin{tabular}{cccccc}
\hline No & Tahun & $\begin{array}{c}\mathrm{Y} \\
\text { (Kunjungan) }\end{array}$ & $\mathrm{X}$ & $\mathrm{X}^{2}$ & $\mathrm{XY}$ \\
\hline 1 & 2013 & 41.553 & -2 & 4 & -83.106 \\
2 & 2014 & 28.802 & -1 & 1 & -28.802 \\
3 & 2015 & 52.439 & 0 & 0 & 0 \\
4 & 2016 & 30.955 & 1 & 1 & 30.955 \\
5 & 2017 & 35.587 & 2 & 4 & 71.174 \\
\hline & Total & 189.336 & & 10 & -9.779
\end{tabular}

Sumber : Data primer diolah, 2018

$$
\begin{aligned}
a= & \frac{\sum Y}{n} \\
& a=\frac{189.336}{5}=37.867,2 \\
b= & \frac{\sum X Y}{X^{2}} \\
& b=\frac{-9.779}{10}=-977,9
\end{aligned}
$$

$\mathrm{Y}=37.867,2-977,9 \mathrm{X}$

Berdasarkan tabel 1. Perhitungan dengan tahun 2015 sebagai dasar perhitungan trend dapat dilihat bahwa akan terjadi penurunan rata-rata jumlah pengunjung sebesar 977,9 orang atau dibulatkan menjadi 978 orang per tahun.

Diperkirakan hal tersebut disebabkan karena fasilitas yang ada di Kawasan Konservasi Mangrove Bekantan di Kota Tarakan mulai rusak seperti jembatan kayu, perpustakaan yang tidak terawat, toilet yang tidak layak pakai, dan lain sebagainya sehingga, apabila tidak dilakukan renovasi dan perbaikan fasilitas maka, pengunjung cenderung tidak memilih Kawasan Konservasi Mangrove Bekantan di Kota Tarakan. Adapun peramalan (Forecasting) jumlah kunjungan Kawasan Konservasi Mangrove Bekantan di Kota Tarakan dalam 5 tahun berikutnya disajikan dalam tabel 2 di bawah ini.
Tabel 2. Hasil Perkiraan Perhitungan Jumlah Kunjungan ke Kawasan Konservasi Mangrove Bekantan Kota Tarakan pada Tahun 2018 - 2022.

Sumber : Data Primer Diolah, 2018

\begin{tabular}{ccccc}
\hline No & Tahun & X & \multicolumn{2}{c}{ Y (Kunjungan) } \\
\hline 1 & 2018 & 3 & Y=37867,2 -977,9(3) & $34.933,5$ \\
2 & 2019 & 4 & $\mathrm{Y}=37867,2-977,9(4)$ & $33.955,6$ \\
3 & 2020 & 5 & $\mathrm{Y}=37867,2-977,9(5)$ & $32.977,7$ \\
4 & 2021 & 6 & $\mathrm{Y}=37867,2-977,9(6)$ & $31.999,8$ \\
5 & 2022 & 7 & $\mathrm{Y}=37867,2-977,9(7)$ & $31.021,9$ \\
\hline & Total & & & $164.888,5$
\end{tabular}

Berdasarkan Tabel 2. dapat disimpulkan bahwa jumlah kunjungan di Kawasan Konservasi Mangrove Bekantan di Kota Tarakan dari tahun 2018-2022 diperkirakan mencapai 164.888,5 pengunjung. Rata-rata penurunan kunjungan per tahun sebanyak 978 orang.

Gambar 2. Grafik Perkiraan Jumlah Kunjungan di

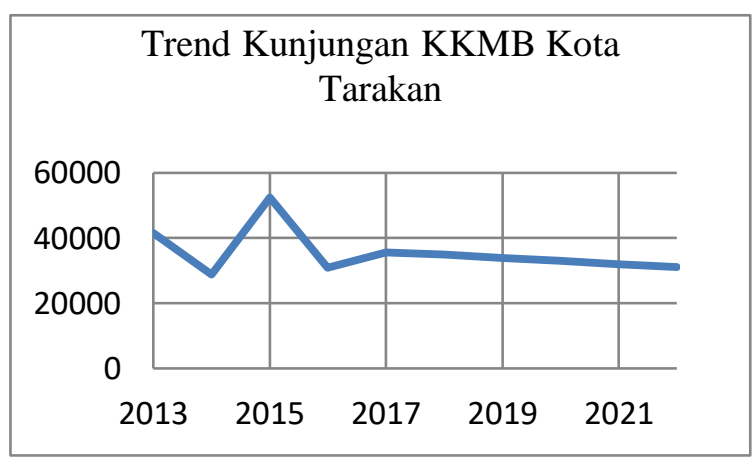

KKMB Kota Tarakan pada tahun 2018 - 2021

Hal ini di sebabkan karena fasilitas yang ada di Kawasan Konservasi Mangrove Bekantan Kota Tarakan kurang memadai seperti jalanan kayu yang mulai rusak dan licin saat hujan, tempat duduk yang kurang, kebersihan yang belum terjaga, toilet yang kurang terawat, serta area parkir yang belum tersedia dengan baik, dan bekantan yang mulai berkurang populasinya. Akan tetapi, walaupun trend 5 tahun mendatang akan diperkirakan jumlah kunjungan wisatawan di KKMB Kota Tarakan berkurang namun hal ini berdampak positif terhadap bekantan (Natalis larvatus) karena, apabila jumlah kunjungan wisatawan berkurang maka, tingkat stress pada bekantan akan berkurang hal ini dikarenakan Kawasan Konservasi Mangrove Bekantan tidak hanya sebagai tempat wisata tetapi juga merupakan Kawasan Konservasi (Pelestarian) Mangrove dan Bekantan di Kota Tarakan.

Hal ini sesuai dengan pernyataan Sunandar (2017) bahwa habitat satwa bekantan 
di Pulau Kalimantan mulai terdesak akibat aktivitas ekonomi masyarakat, ditambah kebijakan pengalihan fungsi lahan untuk pertambakan, perkebunan, pertambangan, perumahan dan juga bekantan tak seperti orang utan yang bisa berpindah tempat saat habitat aslinya rusak maka, bekantan akan mati dan juga para pemodal mengincar area lahan basah dekat sungai atau muara laut agar mudah digunakan dalam sarana transportasi. Penurunan populasi bekantan juga dipengaruhi oleh keberadaan predator bagi bekantan diantaranya biawak (Varanus salvator), macan dahan (Neofelis diardi) (Matsuda, Higashi 2008). Namun kenyataan di lapangan menunjukkan adanya kerusakan hutan mangrove yang cukup memprihatinkan. Kerusakan tersebut terutama disebabkan oleh adanya kegiatan di lingkungan mangrove, seperti perubahan hutan mangrove menjadi penggunaan lain (tambak, pemukiman, dan lain-lain), pencemaran lingkungan (minyak, sampah, dan lain-lain), atau kegiatan lain tanpa memperhatikan kelestariannya. Penebangan hutan mangrove secara besar-besaran untuk dikonversikan menjadi usaha pertambakan dapat menyebabkan terputusnya siklus hidup sumberdaya ikan dan udang di sekitarnya. Berkurangnya ikan dan udang di daerah ini berarti mengurangi pendapatan nelayan-nelayan kecil yang biasanya beroperasi di sekitar pantai, penyudu udang, pencari kepiting dan penjala ikan. Adapun grafik trend kunjungan KKMB Kota Tarakan dapat dilihat pada gambar di bawah ini.

\section{KESIMPULAN}

Berdasarkan uraian hasil dan pembahasan, maka dapat disimpulkan bahwa analisis trend yang dilakukan tahun 2015 sebagai tahun dasar maka, jumlah pengunjung Kawasan Konservasi Mangrove Bekantan di Kota Tarakan dari tahun 2018-2022 diperkirakan mencapai 164.889 pengunjung. Dengan Rata-rata trend penurunan kunjungan per tahun sebanyak 978 orang.

\section{DAFTAR PUSTAKA}

Badan Pengelolaan Lingkungan Hidup. 2010. Laporan Penelitian KKMB Kota Tarakan. Badan Pengelolaan Lingkungan Hidup. Tarakan.

Save Our Environment. 2012. KKMB (Kawasan Konservasi Mangrove Bekantan). http://environmenttheroes.com diakses tanggal 22 September 2018.
Sawitri R, M Bismark Dan E Karlina. 2013. Ekosistem Mangrove Sebagai Obyek Wisata Di Kawasan Konservasi Dan Mangrove Bekantan Di Kota Tarakan. Jurnal Penelitian Hutan Dan Konservasi Alam. Vol 10 No. 3 (297-314).

Subadra. 2008. Ekowisata sebagai Wahana Pelestarian Alam. http//BaliTourismWatch diakses tanggal 21 September 2018.

Sunandar T. 2017. Habitat Satwa Bekantan Di Pulau Kalimantan Timur. Kepala Balai Konservasi Sumber Daya Alam. Kalimantan Timur

Sulistya, AB. 2016. Tren Perkembangan Pariwisata Daerah Istimewa Yogyakarta Periode 20062014. [Skripsi]. Universitas Sanata Dharma. Yogyakarta. [Indonesia]

WTTC. 2016. Travel \& Tourism: Economic Impact 2016 Annual Update Summary. World Travel \& Tourism Council. https://www.wttc.org diakses tanggal 22 September 2018.

Yusuf K. 2008. Sejarah dan pesona alam, kawasan Konservasi Mangrove Bekantan, Tarakan Kalimantan Timur. Pemerintah Daerah Kota Tarakan. Tarakan 